\title{
Peltier'in ısı akış sensörü olarak kullanıldığı ısıl iletkenlik ölçüm metodu
}

\section{Thermal conductivity measurement method using Peltier as heat flow sensor}

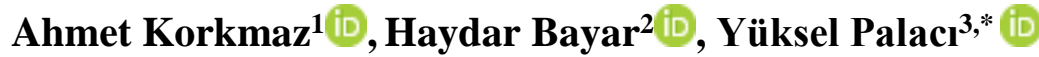 \\ ${ }^{1} 3 P$ Teknoloji Geliștirme ve Danıșmanlık San. Tic. Ltd. Ști., 34896 Istanbul, Türkiye \\ ${ }^{2}$ Yıldız Teknik Üniversitesi, Gemi İsletme Mühendisliği,34353,Beșiktas, İstanbul, Türkive \\ ${ }^{3}$ Yıldız Teknik Üniversitesi, Gemi İnșaatı ve Gemi Makineleri Mühendisliği,34353,Beșiktaș, İstanbul, Türkiye
}

\begin{abstract}
Özet
İnorganik 1sı yalıtım malzemesi geliştirilmesinde, katkılar, oranları, sinterleme sıcaklığı ve süresi gibi birçok parametre çalışıldığından çok sayıda numunenin isıl iletkenliğini ölçmek gerekmektedir. Ayrıca şekillendirilme sonrası da numuneler küçük firında sinterlendiğinden, genellikle kalıp ebatları küçük seçilmektedir. ARGE çalışmalarında bu küçük ebatlı numunelerin 1s1 iletim katsayısını tespit etmeye yönelik uygun maliyette sistem bulmak çok zordur. Bu çalışmada, Peltier'in 1sı akış sensörü olarak kullanıldığ 1 isı iletim katsayısını belirlenmesinde kullanılmak üzere uygun maliyette alternatif cihaz geliştirilmiştir. Ölçüm prensibi, sıcaklıkları farklı iki plaka arasına yerleştirilen numunenin 1s1 iletim katsayısı ile üzerinden geçen 1s1 akışı bir başka deyişle Peltier'den ölçülen gerilim arasındaki orantıdan yola çıkarak belirlenmesine dayanmaktadır. Burada, mutlak 1sı iletim katsayısı bilinen malzemelerin bu düzenekle ölçümünü yapılmış ve sıcak blok ile numune arasına yerleştirilen Peltier'de okunan gerilim arasında korelasyon kurulmuştur. $\mathrm{Bu}$ korelasyon sonrasinda is1 iletkenlik katsayısı hesaplanmıştır. $\mathrm{Bu}$ düzenekle tespit edilen 1s1 iletim katsayısı ile bilinen değerler arasında \%3 seviyelerinde sapma ile numunelerin $1 \mathrm{~s} 1$ iletim katsayısin tespit edilebileceği görülmüştür.
\end{abstract}

Anahtar kelimeler: Peltier, Isıl iletkenlik, Isı akış sensörü, Yalitım

\section{Giriș}

Termal iletkenlik ölçüm teknikleri, termal iletkenlik aralığı, ölçüm süresi, ölçüm doğruluğu, numune türü ve sıcaklık aralı̆̆ına bağlı olarak farklılık gösterdiği görülmektedir. Termal iletkenlik ölçümü için iki ana yöntem mevcuttur [1]. Bunlar kararlı hal yöntemleri ve kararlı olmayan hal yöntemleri yöntemleridir. Kararlı hal yöntemlerinde, numunenin her noktasındaki sıcaklık sabit olduğunda ve sıcaklık zamanla değişmediğinde kararlı durum koşuluna ulaşılmış olur. Gerekli dengeye ulaşmanın genellikle uzun zaman almas1 bir dezavantaj oluşturmaktadır. Ayrıca bu yöntem, iyi tasarlanmış bir deneysel kurulumu gerektirdiğinden yüksek maliyetli aparatları içerir. Ancak, ssıl iletkenlik ölçümünde kullanılan

\begin{abstract}
Since many parameters such as additives, ratios, sintering temperature and time are studied in the development of inorganic thermal insulation materials, it is necessary to measure the thermal conductivity of many samples. In addition, since the samples are sintered in a small furnace after shaping, the mold sizes are generally chosen small. In R\&D studies, it is very difficult to find a cost-effective system to determine the heat transfer coefficient of these small-sized samples. In this study, an alternative device with an affordable cost has been developed to be used in determining the heat transfer coefficient, in which Peltier is used as a heat flow sensor. The measurement principle is based on the determination of the sample placed between two plates with different temperatures, based on the ratio between the heat transfer coefficient and the heat flow passing over it, in other words, the voltage measured from the Peltier. Here, materials with known absolute heat transmission coefficient were measured with this device and a correlation was established between the voltage read in the Peltier placed between the hot block and the sample. After this correlation, the thermal conductivity coefficient was calculated. It has been seen that the heat transmission coefficient of the samples can be determined with a deviation of $3 \%$ between the heat transmission coefficient determined in this arrangement and the known values.
\end{abstract}

Keywords: Peltier, Thermal conductivity, Heat flow sensor, Insulation

birincil ve en doğru yöntemdir. Geçici 1s1 transferi yöntemleri, ısıtma işlemi sırasında doğrudan termal yayılımı belirleme yeteneğine sahiptir. Bu ölçümler nispeten hızlı bir şekilde yapılabilir, bu da diğerlerine göre bir avantaj sağlar.

Kararlı hal yöntemlerinde, 1sı akış ölçerlerin kullanımı, diğer ölçüm teknikleriyle büyük ölçüde aynı ilkelere dayanmaktadır, ancak bunlarla aynı değildir. Isı akış ölçerler doğru ve hızlı cihazlardır ve bu cihazların çalışması düşük iletkenli malzemelerin 1sıl iletkenliğini ölçmek için uygundur. Isı akış ölçer yöntemi için maksimum sicaklık limiti, yaklaşı $1 \mathrm{k} 200^{\circ} \mathrm{C}$ ve pratik uygulamalarda yaklaşı $100^{\circ} \mathrm{C}$ dir [1]. Isı akış ölçer yöntemi karşılaştırmalı ve dolayısıyla göreceli bir yöntem olarak kabul edilebilir. Yalıtım malzemeleri ve polimerler $(\mathrm{k}<0.3 \mathrm{~W} /(\mathrm{m} \mathrm{K}))$

\footnotetext{
* Sorumlu yazar / Corresponding author, e-posta / e-mail: y_palaci@ yahoo.com (Y. Palac1)

Geliş / Recieved: 23.09.2021 Kabul / Accepted: 04.10.2021 Yayımlanma / Published: 14.01.2022

doi: 10.28948/ngmuh.998293
} 
genellikle 1sı akış ölçer yöntemiyle test edilir. Bunun yanında camlar, seramikler ve isıl iletkenlikleri yaklaşık 5 $\mathrm{W} /(\mathrm{mK})$ 'den düşük olan diğer malzemeler için kullanılır. Yaklaşık oda sıcaklığındaki yalıtım malzemeleri için ölçüm belirsizlikleri yaklaşık \%3 tür ve yüksek sıcaklıklarda belirsizlikler $\% 10$ ile $\% 20$ arasındadır [1]. Jonnot vd. [2] düşük örnek boyutlu numuneler için küçük sıcak blok metodunu geliştirmiştir. Bu metod il 3 ila $9 \mathrm{~mm}$ arasında değişen kalınlıklara ve 15 mm'ye kadar düşük çaplar sahip numunelerde $0.014-0.2 \mathrm{~W} /(\mathrm{m} \mathrm{K})$ aralığındaki iletkenlikleri \%10 yanılmayla ölçebilmiştir. Rizzo vd. [3] yaptığı çalışmada ise, temaslı ısı akış sensörlerinin kalibrasyonu ve belirsizliği iyileştirmek önlemler önermiştir. Ölçüm belirsizliğinin bilinen değerden sadece \%2.7 farkl bulunduklarını belirtilmişlerdir.

Isı akış ölçerin temel fikri, bir termal direnç boyunca sıcaklıktaki bir düşüşün ölçümüne dayalı olarak ısı akışının çıkarılmasıdır. Isı akısı ölçümünün yolu, sertifikalı veya iyi bilinen bir referans numunesi ya da bir 1sı akısı sensörü kullanılarak gerçekleştirilir. Isı akısı sensörleri çoğunlukla bir termal direnci kapsayan bir dizi termokupl bağlantısından oluşur. Isı akış sensörlü 1sı iletkenlik ölçüm düzeneği Şekil 1 'de gösterildiği gibi, numune, biri ssıtılan diğeri soğutulan, farklı sicaklıklarda sabit tutulan iki plaka (sıcak ve soğuk blok) arasına yerleştirilir [4]. Kararlı sıcaklıklara ulaşıldığında, sensör kararlı bir elektrik çıkış sinyali sağlar. Ölçülen sinyal ve termovoltajdaki değişiklik, plaka boyunca meydana gelen sıcaklık düşüşündeki düşüşle orantılıdır. Kararlı hal koşulları, katmanlı sistemin her noktasındaki 1sı akısı miktarı eşit olduğunda ortaya çıkar. Termal denge kurulduktan sonra, termal iletkenliği hesaplamak için kararlı hal sıcaklıkları, numunenin kalınlığı, numunenin ölçülen alanı ve sıcak plakaya 1sı akışı girdisi kullanılır. Isı akışı çıkışı genellikle çeşitli referans standartlarıyla, örneğin korumalı bir sıcak plaka aparatında kalibre edilir. Işıker ve Yeşilata [5] araştırmalarında, üç farklı kompozit beton numunesinin birbirine yakın ısı iletim katsayısının farkını ölçebilen hassas bir sistem geliştirmişlerdir. Benzer bir çalışma yapan Sadati ve ark. termoelektrik teknolojisi yani Peltier kullanılarak düşük 1sıl iletkenliğe sahip malzemelerin 1sıl iletkenlik ölçümü için basit, ucuz ve yeni bir yöntem geliştirmişstir [6]. Bu yöntemde kullanılan sistem bir termoelektrik soğutucu, bir termoelektrik jeneratör ve iki fan ile soğutulan iki soğutucudan oluşmaktadır. Termal iletkenliği ölçmek için, bir termoelektrik soğutucu ile bir termoelektrik jeneratör arasına bir numune yerleştirilmiştir. Termoelektrik soğutucunun sıcak tarafında oluşan 1S1 numuneden geçerek termoelektrik jeneratöre girer ve iki tarafi arasında sıcaklık farkı oluşturur.

Sicaklık fark1, termal iletkenliğin, numunenin kalınlığının ve termoelektrik soğutucunun güç tüketiminin bir fonksiyonu olan bir elektrik voltajı üretir. Sonuç olarak, üretilen elektrik voltajının, numunenin kalınlığının, elektrik voltajının ve termoelektrik soğutucunun elektrik akımının bir fonksiyonu olarak termal iletkenliğin tahmini için doğrusal olmayan bir fonksiyon elde etmek için matematiksel bir modelleme kullanılmıştır. Bunun yanında, Austin vd. [7], Peltierin yüzeysel 1s1 akış1 ölçümü için Captec ${ }^{\circledR}$ 1S1 akışı sensörleri ile karşılaştırmıştır.

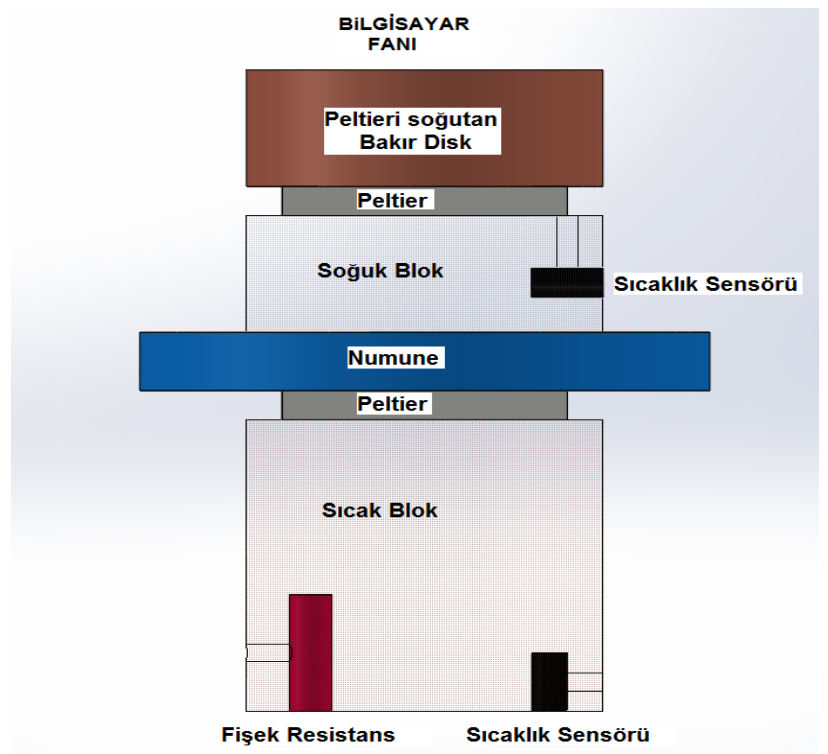

Şekil 1. Test düzeneğinin 2 boyutlu gösterimi

Captec ve Peltier ölçümleri karşılaştırıldığında 1şınımsal kısmın aynı olduğunu bulunmuştur. Bununla birlikte, Peltier ölçümleri kullanıldığında konvektif kısmın, Captec ölçümü kullanıldığından yaklaşık iki kat daha büyük olduğunu tespit etmişlerdir.

Yalıtım malzemesi geliştiren araştırmacılar, malzemeleri ve koşulları değiştirerek çok sayıda deney yapmaktadır. Genellikle seramik inorganik yalıtım malzeme geliştirilmesinde, doğadan temin edilen ucuz ham maddeler yani madenler öğütme veya ayrıştırma işleminden sonra katkılarla karıştırılmakta ve disk şeklinde preslenmektedir. $\mathrm{Bu}$ işlemi takip eden sinterleme ile gerekli mukavemet ve özellikler 1sıtılan disklerde oluşturulmaktadır. Disklerin, 1sı iletkenliklerini ölçerek optimum malzeme ve üretim koşullarını tespit edilmektedir. Ancak, 1sı iletkenlik ölçüm sistemleri ya çok pahalı ya da büyük ebatlı test numunelerinin üretimini zorunlu kılmaktadır. Bu zorluğu ortadan kaldırmak için laboratuvarda inorganik yalıtım malzemeleri geliştiren bilim adamlarının kullanabileceği düşük maliyeti, kolaylıkla kendilerinin oluşturabileceği ve Peltierin 1sı akış sensörü olarak kullanıldığı bir düzenek önerilmektedir.

\section{Materyal ve metot}

Bu çalışmada Peltierin 1sı akış sensörü olarak kullanıldığı bir sistem tasarlanmıştır. Tasarlanan sistemin çalıştığ ortamın sıcaklığı ölçüm sonuçlarını etkilememesi için $22^{\circ} \mathrm{C}$ 'de sabit tutulmuştur. Numune yüzeylerindeki sicaklık fark1 10 derece olarak ayarlandığı için, soğuk tarafa doğru 1s1 akışı olmaktadır. Bu 1sı akışı numunenin sıcak tarafında bulunan Peltierde gerilim oluşturmaktadır. $\mathrm{Bu}$ gerilim değerinden 1sıl iletkenlik katsayısı tahmin edilmektedir. Pazarda mevcut Peltierlerin genel ebatları 40mmx40mm olduğundan 1sıl iletkenlik ölçümü yapılacak numune ebatları bundan büyük olmalıdır. Soğuk tarafın sıcaklığını belli bir seviyede tutmak için diğer bir Peltier soğutucu olarak kullanılmaktadır. Sıcak bloğun 1sıtılması için ise alt bloğun içerisine 3D yazıcı 1sıtıcısı olarak kullanılan bir adet fişek 
rezistans yerleştirilmiştir. Soğuk ve sıcak taraflardaki sicaklık kontrolü ve ölçümü için her birine bir adet LM35 analog sıcaklık sensörü yerleştirilmiştir. Isı akışı blokları ise bakır disklerden meydana gelmektedir.

\subsection{Sistem tasartmı}

Çalışmada düzenek $22^{\circ} \mathrm{C}$ 'de sıcaklığg sabit tutulan 50 mm kalınlığında, iç ölçüleri( 300 mm X 300 mm X 150 mm) bir yoğunluğu $30 \mathrm{~kg} / \mathrm{m}^{3}$ strafor kutu içerisinde gerçekleştirilmiştir. Yapılan kapalı düzeneğin içinde sıcak blok tarafi gömülü halde ve sabitlenmiştir. Sıcak bloğun üzerine sensör olarak kullanılacak Peltier yerleştirilmiştir. Ölçülecek numune Peltierin üzerine yerleştirilmektedir. Daha sonra numunenin üzerine diğer bir Peltier tarafından soğutulan blok yerleştirilmektedir. $\mathrm{Bu}$ blok içerisinde de sicaklık sensörü bulunmaktadır. Her iki bloğun da sicaklıkları PID denetleyici ile sabit tutulmaktadır.

Tasarlanan test düzeneğinin çalışma prensibini şöyle ifade edebiliriz. EPS malzemeden yapılan küp şeklinde üst yüzeyi açık malzemenin alt tarafında bulunan parça sıcak tarafi temsil etmektedir. Alt sicak blok basit bir 1sitıc1 yardımıyla sıcaklığı sabit kalacak şekilde PID kontrolü ile 1sıtılmaktadır. Ölçüm sırasında test ortamının sıcaklığg $22^{\circ} \mathrm{C}$ derece olduğundan, sicak bloğun sicaklığı 5 derece daha yüksek olarak $27^{\circ} \mathrm{C}$ dereceye ayarlanmıştır. Soğuk blok ise ortam sıcaklığının 5 derece altı olan $17^{\circ} \mathrm{C}$ 'ye ayarlanmıştır. Böylece toplam sıcaklık farkı 10 derece olacak şekilde, sıcak taraf $27^{\circ} \mathrm{C}$ ve soğuk taraf $17^{\circ} \mathrm{C}$ derece olarak ayarlanmıştır. Set edilen sıcaklıklara ulaşılması ve sıcaklık farkının $10^{\circ} \mathrm{C}$ 'de sabit kalması ile Peltierin üzerindeki gerilim ölçümü için geçen süre yaklaşık olarak 7-8 dakika olarak tespit edilmiştir. Ayrıca soğuk tarafın sıcaklığını sabitlemek için bu bölgede Peltierin üstünde oluşan 1sı bilgisayar fan sistemi kullanılarak uzaklaştırılmaktadır. Sistem dengeye ulaştığında ölçüm için kullanılan Peltierin üzerinden akan 1Sı sabit olacaktır. Bunun sonucunda Peltierin uçlarından bir gerilim oluşmaktadır ve bu gerilim akan ısının miktarıyla orantılıdır. Bu akan 1sının miktarı ve dolayısı ile Peltier gerilimi numunenin termal iletkenliği ile ilişkilidir. Sistemdeki parçaların konumunu ve test düzeneğinin son hali Şekil 2'de görülmektedir.

\section{2 Ölçülen numuneler}

Çeşitli karışımlar sonucu elde edilen seramik, dairesel geometriye sahip 60-100 mm çap aralığında ve 6-12 mm aralığında kalınlığa sahip numunelerin (Şekil 3) flaş lazer ölçüm tekniği kullanılarak elde edilmiş 1sıl iletkenlik katsayılarının (k (W/m.K)) peltiyerin sensör olarak kullanıldığ 1 ölçme sisteminde tekrar ölçümü yapılmış ve bu ölçümler karşılaştırılmalı olarak gösterilmiştir.

\subsection{Elektronik kart ve program}

Test sisteminde STM32F103C6T6 micro denetleyici geliştirme kartı kullanılmıştır. Peltier ve sıcaklık sensörlerinden gelen anolog veriler ADS1115 analog dijital dönüştürücü modülüyle mikro denetleyiciye aktarılmıştır.

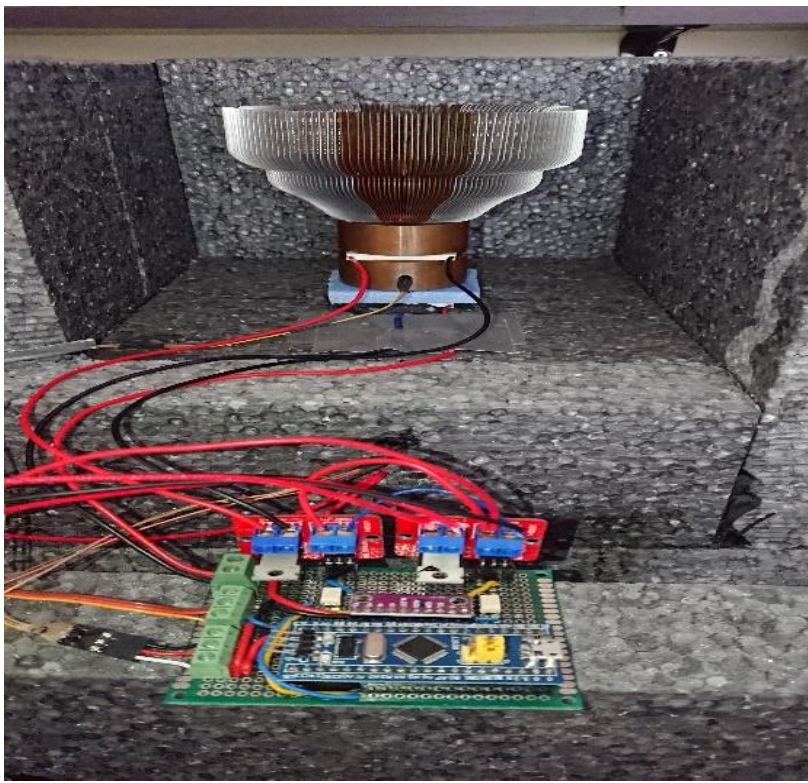

Şekil 2. Isı iletkenliği ölçüm test düzeneği

Bu modül 15 bit çözünürlüğünde olup $0.015 \mathrm{mV}$ hassasiyetle çalışmaktadır. Fişek 1sıtıcıyı ve soğutma amaçlı kullanılan Peltieri sürmek için IRF520N mosfetleri kullanılmıştır.

\subsection{Kalibrasyon için kullanılan test malzemeleri}

\subsubsection{Farklı kalınlıkta hazırlanan malzemeler}

Çalışmada 1sıl iletkenlik katsayısı ölçümü yapılacak malzemelerin kalınlığı değiştiğinden dolayı, kalınlık ile okunan Peltier gerilimi arasında bir bağıntı çıkarılması gerekmektedir. Test sistemi yaklaşık $10 \mathrm{~mm}$ kalınlığındaki numuneleri ölçmek amacıyla tasarlandığından dolayı, $8 \mathrm{~mm}$, $9 \mathrm{~mm}, 10 \mathrm{~mm}, 11 \mathrm{~mm}$ ve $12 \mathrm{~mm}$ kalınlığında kağıt bloklar kalibrasyon ölçümü için hazırlanmıştır.

\subsubsection{Farkl isl iletkenliğe sahip malzemeler}

Isıl iletkeliğin ölçümünde, Peltier 1sı akış sensörü gerili ile 1sıl iletkenlik ilişkisinin tespit edilmesi ve buna göre kalibre katsayısı bulunması için ısıl iletkenliği belirli olan ve farklı ısıl iletkenlik katsayısına sahip, farklı kalınlıklarda malzemeler kullanılmıștır. Kullanılan malzemeler Tablo 1'de listelenmiştir. 3 adet farklı k değerlerine sahip numune (2 seramik, 1 EPS) bilinen değerlerinden yola çıkarak Peltierin gerilimi ile termal iletkenlik arasında korelasyon kurulmuştur. Böylece ölçüm yapılıp Peltier üzerindeki gerilimine etkisi kalibre edilmiştir. Sonuçlar Tablo 1'de gösterilmiştir.

Tablo 1. Farklı 1sıl iletkenlik ve kalınlığa sahip malzemeler

\begin{tabular}{ccc}
\hline Malzeme & $\begin{array}{c}\text { Isıl iletkenliği } \\
(\mathrm{W} / \mathrm{mK})\end{array}$ & Kalınlı̆̆ $(\mathrm{mm})$ \\
\hline 1 & 0.032 & 10.00 \\
2 & 0.153 & 10.90 \\
3 & 0.272 & 11.43 \\
\hline
\end{tabular}




\subsubsection{Maliyet dă̆gllımı}

Kullanılan malzemelerin maliyet dağılımları Tablo 2'de verilmektedir. Burada maliyet dağılımında elektronik kısmın maliyeti aşağı yukarı bakır maliyetine yakındır. Toplamda ise 850 TL (\$100) karşılık yapılabileceği görülmektedir.

Tablo 2. Isı iletkenlik ölçüm sistemi maliyetleri

\begin{tabular}{lcccc}
\hline \multicolumn{1}{c}{ Ürün } & \multirow{2}{*}{ Adet } & $\begin{array}{c}\text { Fiyat } \\
\text { TL }\end{array}$ & $\begin{array}{c}\text { Toplam } \\
\text { TL }\end{array}$ & $\begin{array}{c}\text { Toplam } \\
\$\end{array}$ \\
\hline Peltier & 2 & 42 & 84 & 10 \\
Bakır malzeme & 3 & 80 & 240 & 30 \\
Bakır işçiliği & 1 & 240 & 240 & 30 \\
Fişek rezistans & 1 & 8 & 8 & 1 \\
Sicaklık sensörü & 2 & 8 & 16 & 2 \\
Bilgisayar fanı & 1 & 40 & 40 & 5 \\
Mikro denetleyici & 1 & 40 & 40 & 5 \\
Mosfet & 2 & 20 & 40 & 5 \\
Analog-dijital dönüştürücü & 1 & 25 & 25 & 3 \\
Diğer masraflar & 1 & 85 & 85 & 10 \\
TOPLAM & & & & 100 \\
\hline
\end{tabular}

\section{Bulgular ve tartışma}

Numune sonuçlarının değerlendirebilmesi için öncelikle sistemde Peltier geriliminin süreye bağlı değişimi incelenmiş ve sistemin kararlı hale gelmesi için gereken süreye bakılmıştır. Peltier geril değeri kullanılırken gerilimin kararlı hale geçtiğinde okunan gerilim değeri alınmıştır. Karalı hale gelmesinin gösterildiği grafik Şekil 3'de gösterilmiştir. Ortalama 8 dakikada okunan gerilim değeri değişimi minimize olup kararlı hale gelmektedir.

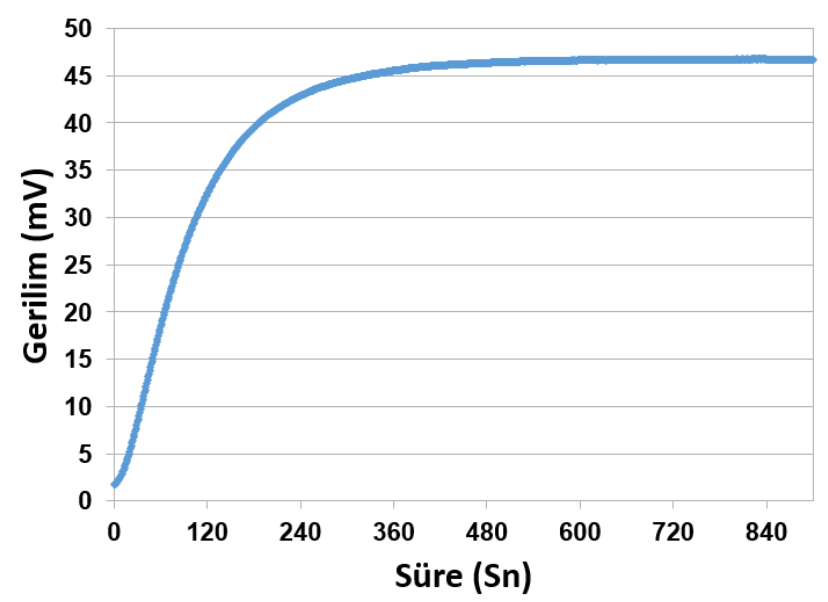

Şekil 3. Okunan gerilimin kararlı hale gelme süresi

\subsection{Kalınlık kalibrasyonu}

Ölçülecek numunelerin kalınlığı sabit olmadığından, Peltierden ölçülen gerilim de kalınlığa göre değişecektir. Bu kalınlık etkisini minimize etmek için $8 \mathrm{~mm}, 9 \mathrm{~mm}, 10 \mathrm{~mm}$, $11 \mathrm{~mm}$ ve $12 \mathrm{~mm}$ kalınlığındaki kâğıt blokları ile ölçümler alınmış ve kalınlık ile Peltier gerilim arasındaki ilişki çıkarılmıştır. Tablo 3'de bu kalınlık ve gerilim değerleri verilmekle beraber, referans alınan $10 \mathrm{~mm}$ kalınlığa göre gerilim değişimin oranı da gösterilmiştir. Ayrıca Şekil 4'te kalınlığa karşı okunan sensör gerilim değerlerinin (Gs) dağılımının verildiği grafik görülmektedir. Kalınlık attıkça ölçülen geriliminde lineer bir ilişki ile azalması beklendiğinden ölçüm değerleri Excel programı kullanılarak, lineer bir ilişki fonksiyona dönüştürülmüştür. Fonksiyon Denklem 1'de verilmiştir. Denklem 1'de hesaplanan Ç1 değeri kalınlığa göre düzeltme katsayısı çarpanı olarak hesaplanmaktadır. Sensör gerilim değerleri (Gs) ise Peltier 1sı akış sensöründen okunan değerdir.

$$
\text { Ç1 }=-0.917(\mathrm{Gs})+1.9393
$$

Tablo 3. Farklı kâğıt kalınlıkları için Peltier gerilim değerleri ve düzeltme katsayıları

\begin{tabular}{cccc}
\hline Numune & $\begin{array}{c}\text { Kalınlık } \\
(\mathrm{mm})\end{array}$ & $\begin{array}{c}\text { Peltier sensör gerilim } \\
\text { Değeri(Gs) }(\mathrm{mV})\end{array}$ & $\begin{array}{c}\text { Düzeltme } \\
\text { Çarpanı }\left(\mathrm{C}_{1}\right)\end{array}$ \\
\hline 1 & 8 & 30.6 & 1.207 \\
2 & 9 & 28.7 & 1.132 \\
3 & 10 & 25.36 & 1.000 \\
4 & 11 & 23.33 & 0.920 \\
5 & 12 & 21.66 & 0.854 \\
\hline
\end{tabular}

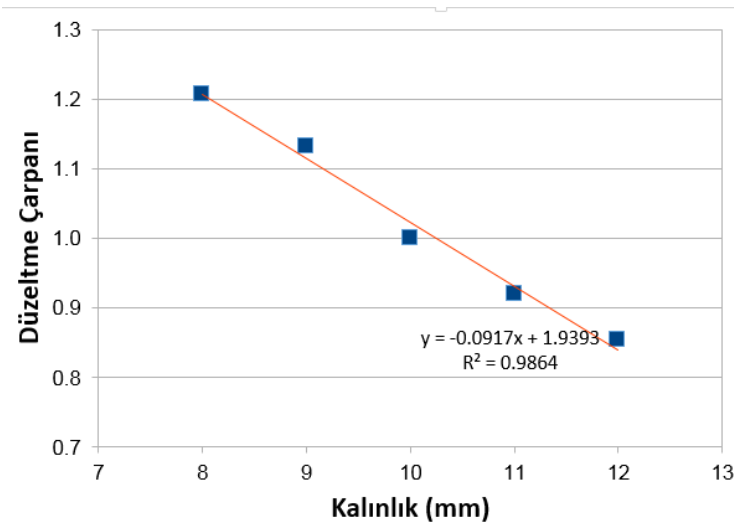

Şekil 4. Kalınlığa karşı okunan gerilim değerleri dağılımı ve bu ilişkiyi en iyi tanımlayan lineer fonksiyon

\subsection{Isı iletim katsayısı Kalibrasyonu}

Isı iletim katsayısına bağlı olarak Peltier 1sı akış sensörünün kalibrasyonu için 1s1 iletim katsayısı bilinen 3 farklı numune için öncelikle kalınlıklarının çarpanı bulunmuş ve buna göre değerleri düzeltilmiştir. Daha sonra Excel programı yardımı ile bilinen 1sı iletkenlik değerleri(k) (W/mK) okunan kalınlık çarpanı ile düzeltilmiş gerilim değerleri(Gk) Denklem 2'de görüldüğü gibi hesaplanmıştır. Isı iletim katsayısı kalibrasyonu için kullanılan numunelerin bilinen ısı iletim katsayısı ve kalınlığa göre düzeltilmiş gerilim değerleri Tablo 4'de dağılımı ise Şekil 5'deki grafikte verilmiştir. Excel programı ile hesaplanan dağılıma en iyi tarifleyen ikinci derece polimon Denklem 3'de verilmiştir. Burada K gerilimden yola çıkarak hesaplana ısı iletim katsayısını vermektedir.

$$
\mathrm{Gk}=\mathrm{Gs} / \mathrm{C} 1
$$

$$
\mathrm{K}=-2 \mathrm{E}-05(\mathrm{Gk}) 2+0,0079(\mathrm{Gk})-0,0403
$$


Tablo 4. Numunelerin bilinen 1s1 iletkenlik katsayıs1 ile kalınlık düzeltmesi yapılmış gerilim değerleri

\begin{tabular}{cccccc}
\hline Numune & $\begin{array}{c}\text { Gerçek } \\
\text { "k" } \\
\text { Değeri }\end{array}$ & $\begin{array}{c}\text { Ölçülen Peltier } \\
\text { Gerilim (Gs) } \\
(\mathrm{mV})\end{array}$ & $\begin{array}{c}\text { Numune } \\
\text { Kalınlığı } \\
(\mathrm{mm})\end{array}$ & $\begin{array}{c}\text { Kalınlık } \\
\text { Çarpanı } \\
(\mathrm{Ç1)}\end{array}$ & $\begin{array}{c}\text { Düzeltimiş } \\
\text { Peltier } \\
\text { Gerilimi } \\
(\mathrm{Gk})\end{array}$ \\
\hline 1 & 0.032 & 9.57 & 10.00 & 1.022 & 9.360 \\
2 & 0.153 & 24.75 & 10.90 & 0.940 & 26.331 \\
3 & 0.272 & 40.24 & 11.43 & 0.891 & 45.144 \\
\hline
\end{tabular}

\subsection{Isı iletim katsayısı ölçümü ve karşılaştırma}

Daha önce lazer flash yöntemiyle 1sıl iletkenliği ölçülmüss 11 seramik ve 1 adet XPS yalıtım malzemesinin ölçümleri tasarlanan sistem ile yapılmıştır. Tablo 5'de, sensör gerilim değerleri (Gs), kalınlık düzeltme çarpanı (Ç1), düzeltilmiş gerilim (Gk) ve hesaplanan termal iletkenlik (K) değerleri verilmiştir. Hesaplanan 1sı iletim katsayısı ile lazer flash yöntemiyle ölçülen değerlerin dağılımı Şekil 6' verilmiştir. Görüleceği üzere hesaplanan değerlerle bilinen değerler arasında en fazla $\% 5.62$ gibi bir farkl1lık olabilmektedir.

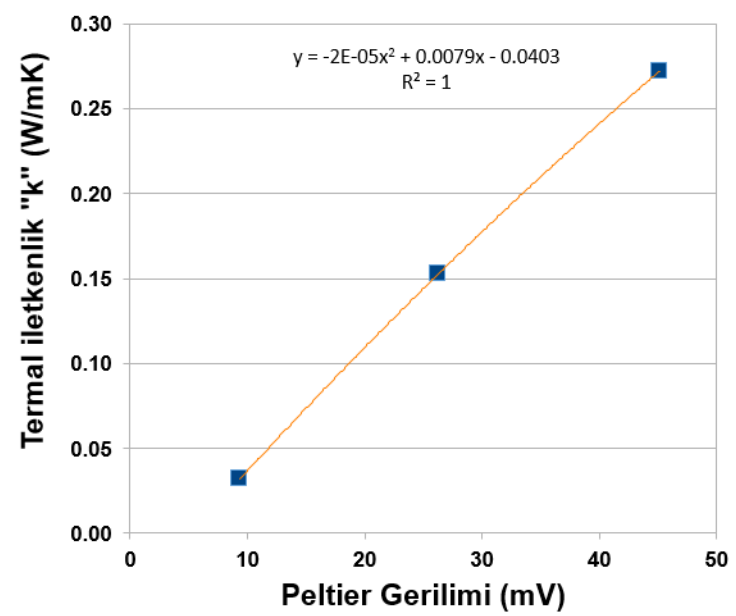

Şekil 5. Kalınlığa göre düzeltilmiş gerilim değerlerine karşı 1sı iletim katsayıları grafiği

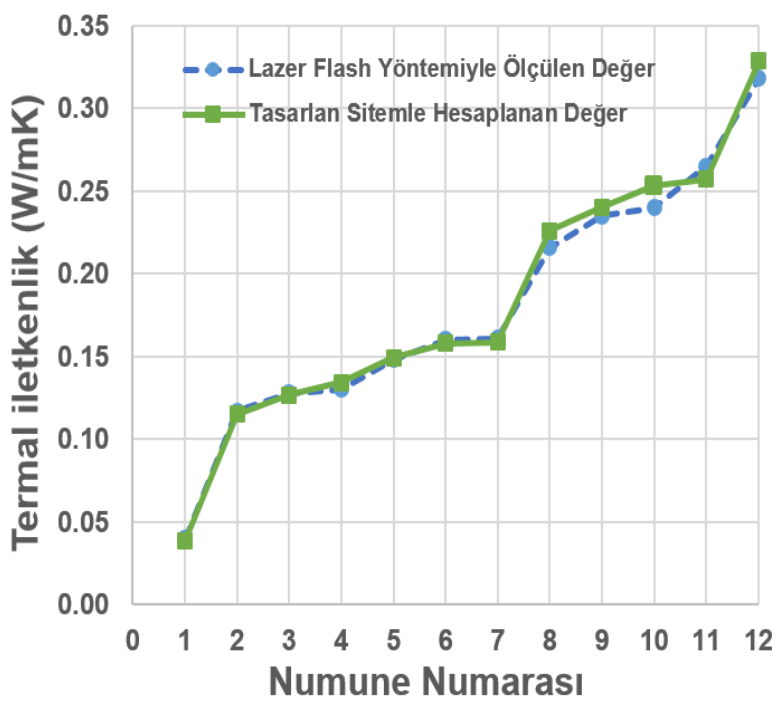

Şekil 6. Numunelerin kalınlıklarına göre hesaplanan ve bilinen ısı iletkenlik katsayısı dağılımı grafiği

\section{Sonuçlar}

Yalıtım uygulamalarında kullanılan materyal ya da malzemelerin 1sıl iletkenlik ölçümüne yönelik bu yöntem oldukça ekonomik ve diğer yöntemin çıtılarına yakın sonuçlar vermektedir. Bu çalışmada incelenen Peltierin 1sı akış sensörü olarak kullanıldığı ölçüm yöntemi; ölçüm hassasiyeti, küçük boyutlu numune kullanımı ve deney süresinin kısalığı nedeniyle tercih edilebilir. Ayrıca çoklu sistem tasarımına uygun bir düzenektir.

Tablo 5. Farklı kalınlıklarda ve farklı ısı ilesim katsayısına sahip numunelerin hesaplanan değerlerleri

\begin{tabular}{|c|c|c|c|c|c|c|c|}
\hline Numune Sira no & $\begin{array}{c}\text { Ölçülen Peltier } \\
\text { Gerilimi }\end{array}$ & $\begin{array}{l}\text { Numune Kalınlığ } \\
\quad(\mathrm{mm})\end{array}$ & $\begin{array}{c}\text { Kalınlık Düzeltme } \\
\text { Oranı }\end{array}$ & $\begin{array}{l}\text { Düzeltimiş Peltier } \\
\text { Gerilimi }\end{array}$ & $\begin{array}{c}\text { Ölçülen "k" } \\
\text { Değeri }\end{array}$ & $\begin{array}{l}\text { Gerçek "k" } \\
\text { Değeri }\end{array}$ & Sapma \% \\
\hline 1 & 11.400 & 9.0 & 1.114 & 10.232 & 0.039 & 0.040 & 3.66 \\
\hline 2 & 24.870 & 8.1 & 1.197 & 20.783 & 0.115 & 0.117 & 1.82 \\
\hline 3 & 21.740 & 10.6 & 0.967 & 22.492 & 0.127 & 0.128 & 0.96 \\
\hline 4 & 27.620 & 8.4 & 1.173 & 23.550 & 0.134 & 0.130 & 3.12 \\
\hline 5 & 29.200 & 8.8 & 1.132 & 25.784 & 0.149 & 0.148 & 0.88 \\
\hline 6 & 28.000 & 9.9 & 1.034 & 27.069 & 0.158 & 0.160 & 1.27 \\
\hline 7 & 27.100 & 10.3 & 0.997 & 27.187 & 0.159 & 0.161 & 1.39 \\
\hline 8 & 34.260 & 11.2 & 0.912 & 37.547 & 0.226 & 0.216 & 4.57 \\
\hline 9 & 46.750 & 8.4 & 1.172 & 39.892 & 0.240 & 0.235 & 2.29 \\
\hline 10 & 56.100 & 6.6 & 1.334 & 42.048 & 0.254 & 0.240 & 5.63 \\
\hline 11 & 36.220 & 11.9 & 0.849 & 42.652 & 0.257 & 0.265 & 2.96 \\
\hline 12 & 76.400 & 6.0 & 1.386 & 55.105 & 0.329 & 0.318 & 3.32 \\
\hline
\end{tabular}




\section{Not}

$\mathrm{Bu}$ makale birinci yazar Ahmet Korkmaz'in yüksek lisans çalışmasından üretilmiştir.

\section{Çıkar çatışması}

Yazarlar çıkar çatışması olmadığını beyan etmektedir.

\section{Benzerlik oranı (iThenticate): \%13}

\section{Kaynaklar}

[1] N. Yüksel, The review of some commonly used methods and techniques to measure the thermal conductivity of insulation materials, Insulation Materials in Context of Sustainability, IntechOpen 2016. https://doi.org/10.5772/64157

[2] Y. Jannot,1, S. Schaefer, A. Degiovanni, J. Bianchin, V. Fierro, and A. Celzard, A new method for measuring the thermal conductivity of small insulating samples, Review of Scientific Instruments, 90, 054901-9, 2019. https://doi.org/10.1063/1.5065562

[3] G. Rizzo, R. Christen, and M. Stöck, Calibration methodology for contact heat flux sensors with enhanced accuracy, Measurement Science and Technology, 32(4), 045003, 2021. https://iopscience. iop.org/article/10.1088/1361-6501/abcf62
[4] 2019ASTM C518-17, Standard Test Method for Steady-State Thermal Transmission Properties by Means of the Heat Flow Meter Apparatus, ASTM International, West Conshohocken, PA, 2017. https://doi.org/ 10.1520/C0518-17

[5] Y. Iş̧ıer, ve B. Yeşilata, Yapı malzemelerinin isı iletim katsayılarının tespitine yönelik yeni bir yöntem geliştirilmesi, Harran Unv. Muh. Der., 01, 14-21, 2017. https://dergipark.org.tr/tr/pub/humder/issue/30491/341 142

[6] S. Sadati, N. Rahbar H. Kargarsharifabad, and K. Doost, Low thermal conductivity measurement using thermoelectric technology - Mathematical modeling and experimental analysis, International Communications in Heat and Mass Transfer, 127, 2021. https://doi.org/10.1016/j.icheatmasstransfer. 2021.105534

[7] M. Austin, T. Vogt, W. A. Sempey, A. Sommier, ve J. Dumoulin, Investigation into the use of thermoelectric modules as an alternative to conventional flux meters: application to convective and radiative heat flux in buildings. International Journal of Thermal Sciences, 160, 1-13, 2021. 